\title{
O ESTÍMULO PSICOMOTOR POR MEIO DE BRINCADEIRAS PEDAGÓGICAS E OS RESULTADOS NO PROCESSO DE ALFABETIZAÇÃO
}

\author{
Autoras: \\ Karine Locateli dos Santos \\ Faculdade de Mauá-Fama \\ karine-04@ hotmail.com \\ Marcia Cristina Madureira de Andrade \\ Faculdade de Mauá-Fama \\ marciamaddureira@gmail.com \\ Vanessa Leite da Silva \\ Faculdade de Mauá-Fama \\ vanessaleiterh@gmail.com
}

Orientadora:

Maria Madalena Pimentel

\section{RESUMO}

Evidenciar os benefícios dos estímulos psicomotores, por meio de brincadeiras pedagógicas mediadas na educação infantil, e seus resultados no processo de alfabetização. A brincadeira ajuda a criança a descobrir, como é o seu mundo de invenções, desenvolvendo as quatro áreas: cognitiva, afetiva, motora e social. Pois a mesma disponibiliza atenção a tudo o que ocorre ao redor, é fundamental para que se conheça o mundo de forma mais ampla, e sua necessidade para o desenvolvimento, permite que as crianças realizem ações, e aos poucos, organizem suas relações emocionais e sociais, usando sua imaginação e criatividade. Sendo o professor peça chave como mediador, na formação do sujeito, utilizando de suas habilidades e competências, proporcionando ao indivíduo condições de desenvolver por meio do corpo sentido, ou seja, conhecer seu corpo para a partir daí contextualizar o mundo que o cerca. 
Palavras-chave: Alfabetização, Aprendizagem, Brincadeiras Pedagógicas, Psicomotricidade

\begin{abstract}
To demonstrate the benefits of psychomotor stimuli, through pedagogic games mediated in early childhood education, and their results in the literacy process. The play helps the child to discover how his world of inventions is, developing the four areas: cognitive, affective, motor and social. Because it pays attention to everything that happens around, it is fundamental for the world to be known more broadly, and its need for development, allows children to take action, and gradually organize their emotional and social relationships, using your imagination and creativity. Being the teacher plays the key as a mediator, in the formation of the subject, using his skills and abilities, providing the individual conditions to develop through the sense body, that is, to know his body to from there to contextualize the world that surrounds him.
\end{abstract}

Keywords: Literacy, Learning, Pedagogical Games, Psychomotricity

\title{
INTRODUÇÃO
}

O presente artigo visa constatar os benefícios da brincadeira pedagógica como estímulo psicomotor para a aprendizagem desenvolvendo habilidades que reflitam na alfabetização do aluno, assim como, a importância do estímulo psicomotor por meio da brincadeira pedagógica para o processo de alfabetização das crianças de 3 a 5 anos. E verificar possibilidades de transformações nas propostas pedagógicas que expressem as variadas formas de movimento, e em que momento as ações pedagógicas podem contribuir para o estímulo da motricidade infantil que é de suma importância em sua construção.

Esta pesquisa se justifica pela necessidade de analisar os benefícios dos estímulos psicomotores, por meio de brincadeiras mediadas na educação infantil, e seus resultados no processo de alfabetização, e avaliar suas adaptações, despertando o interesse da criança ao novo, pois no ambiente escolar encontram-se abertas a receber o conhecimento e a interagir com o professor, sendo o lúdico uma estratégica que potencializa a aprendizagem, trabalhando o seu desenvolvimento psicomotor como coadjuvante no processo de alfabetização.

A abordagem utilizada para a pesquisa será a exploratória com levantamento bibliográfico, com o objetivo de aprofundar o tema, que apresenta o embasamento teórico de autores renomados. 


\section{A BASE NACIONAL COMUM CURRICULAR (BNCC)}

De acordo com os dados levantados pela revista nova escola de fevereiro de 2018, é possível perceber a importância da Base Nacional Comum Curricular (BNCC) para educação atual, pois procura garantir e atualizar os conteúdos aplicados com qualidade e equidade a todos conforme o documento, a criança será alfabetizada em dois anos, ou seja, aos oito anos de idade a criança tem que ler e interpretar textos básicos.

Segundo NISTA-PICCOLO (2013, p.50), é de extrema importância a contextualização de direitos com a vivencia da criança durante o processo de escolarização em que as disciplinas que contemplam o currículo escolar priorizem a corporeidade como princípio básico, colocando a ação do professor como ferramenta mediadora.

Utilizando o ensino/aprendizagem flexível, em que o professor possa promover possibilidades de explorar o lúdico cultural, pois a imaginação e a criatividade da criança não têm limite, tornando um facilitador para a construção da sua personalidade.

O trabalho com a brincadeira na educação infantil é um dos passos para cultivar essa vitalidade natural da criança e auxiliar em sua alfabetização. Por isso entendemos que pesquisar o uso das brincadeiras pedagógicos é o que contribuirá para que o educador promova uma aula mais dinâmica por meio de estratégias lúdicas.

\section{A APRENDIZAGEM POR MEIO DOS ESTÍMULOS}

De acordo com NISTA-PICCOLO (2013, p.41), a aprendizagem se dá por meio das interações sociais e tudo aquilo que o sujeito vivência no seu contexto e que tenha um significado, sendo assim, as características não são herdadas biologicamente e sim são construídas socialmente e historicamente.

Desta forma a contribuição para uma aprendizagem eficaz na formação do indivíduo acontece por meio de tudo aquilo que ele vivencia em seu contexto histórico, e com os estímulos aplicados de forma correta, a criança além de uma integração social, ela desenvolverá também cognitivamente, o afetivo, e o motor, com isso, ela terá um leque maior de possibilidades pois conhecerá suas potencialidades, e se expressará por meio seus movimentos. 
Acredita-se que a integração da criança com as brincadeiras pedagógicas contribui para o seu desenvolvimento e amadurecimento, tanto da alfabetização, quanto de senso crítico, formando um cidadão capaz de agir e atingir objetivos.

O professor tem um papel primordial, pois através da brincadeira é possível avaliar e compreender as necessidades, interesses e potenciais de cada criança, facilitando a relação professor e aluno.

Sendo assim, é necessário investir em estímulos motores e observar maneiras de auxiliar a criança no seu desenvolvimento psicomotor, tendo em vista que ato mental se desenvolve a partir do ato motor, ou seja, a criança a partir do momento que conhece o seu corpo, ela vai desenvolver a motricidade, suas habilidades e o tônus muscular, conseguindo dosar a força necessária para movimentar certas partes do corpo, como se movimentar ou sentar-se, segurar um copo com água, a criança vai desenvolver a sua coordenação motora grossa (global), que são os movimentos mais amplos, e como consequência irá desenvolver sua coordenação motora fina, que a ajudará a segurar um lápis da maneira correta para conseguir executar a escrita. Identificou-se que as dificuldades encontradas pelos alunos, durante no processo de alfabetização, pode estar associado a falta de noção espacial, devido a distúrbios no desenvolvimento corporal, ora, a falta de conhecimento de seu corpo.

Para NOGUEIRA, 2007:

É possível que as dificuldades encontradas pelas crianças no período de alfabetização estejam associadas a falta de noção espacial, devido a distúrbios de desenvolvimento corporal (levantamento feito com crianças de 3 a 7 anos de educação infantil ao $1^{\circ}$ ano do ensino fundamental), com o intuito de diagnosticar potencialidades e defasagens.

\section{AS AÇÕES AUXILIAM NA AUTONOMIA DA CRIANÇA.}

Segundo (NOGUEIRA, 2007), a criança que reconhece o próprio corpo tem desenvolvida a noção espacial, isso facilita o desenvolvimento da mesma tornando o processo de alfabetização natural.

A partir de ações rotineiras como descascar uma banana, rasgar um papel, promover a autonomia e independência da criança, assim como, a higiene pessoal, o 
auxílio nas tarefas de casa guardando seus brinquedos, colocando a roupa sozinha, quanto na escola ao tomar seu lanche, escovação dos dentes, ou executando tarefas propostas pelo professor, são tarefas primordiais para o desenvolvimento da motricidade passando do processo de atos reflexos para atos intencionais, ou seja, estabelecendo a construção cognitiva, desenvolvendo também a lateralidade e noção espacial na criança.

A interação com o lúdico agrega valores para o desenvolvimento cognitivo da criança, pois saber ler uma imagem, ver um filme, ouvir um CD, é tão importante quanto saber ler e escrever. No mundo em que vivemos é importante que as crianças estejam preparadas para explorar e interpretar o universo dessas linguagens, para auxiliá-las nas descobertas geradas pelo meio de comunicação.

O brincar existe na vida dos seres humanos, desde a antiguidade, porém com o passar do tempo esse "brincar" passou por uma série de transformações e adaptações por conta do espaço em que o sujeito vive e o tempo que ele tem.

A sociedade moderna se modifica constantemente, deixando de lado a essência e a inocência das crianças, ou seja, com o avanço das novas tecnologias, as crianças ficam entretidas por um longo tempo e não veem outra coisa a não ser a determinado aparelho tecnológico, por exemplo: a televisão, vídeo game, computador, celular etc.

Essa transformação é benéfica para a sociedade em geral, mas em alguns momentos ela veda o que se tem de melhor, sem ser preciso ir muito longe para conseguir, que é o brincar.

O envolvimento do professor é indispensável para o ensino, um momento de interação, em que o educador tem a possibilidade de introduzir e mediar novos saberes por meio de brincadeiras para a criança.

Nista-Piccolo (2013, p.38) ressalta que:

“O esquema corporal que é o núcleo central da personalidade, e a partir dele é que se organizam os comportamentos, as condutas e todos os conhecimentos. Conforme as experiências vividas pela criança, o seu esquema vai sendo construído e se torna o elemento básico da formação de sua personalidade. Significa a representação diferenciada que ela tem do próprio corpo. Ela percebe a si mesma e aos outros ao seu redor em função de sua pessoa. Quanto mais ela 
domina os movimentos do próprio corpo, mais se encanta com as suas possibilidades de agir e se propõe a mais experiências."

\section{4- A IMPORTÂNCIA DO PROFESSOR COMO MEDIADOR NO DESENVOLVIMENTO MOTOR}

As mudanças educacionais têm acontecido moldadas pela globalização, que refletem no sistema educacional, evidenciando a modernidade competitiva em que o professor está inserido.

Atualmente é exigido uma capacitação contínua que vai além da sua graduação como pedagogo, visto que é um profissional capacitado a mediar situações que favoreçam o desenvolvimento cognitivo e motor. Para tanto é esperado que o mesmo tenha uma formação e qualificação que atendam às necessidades do sujeito em desenvolvimento.

O professor precisa desenvolver um olhar pedagogicamente apurado, mantendose atento as novas descobertas e sempre atualizado, para suprir as exigências das crianças, pois é função desse profissional priorizar suas habilidades e competências para atingir o desenvolvimento psicomotor do aluno em questão, proporcionando um reflexo positivo durante o processo de alfabetização.

É fundamental que além de uma formação acadêmica englobe a prática com a teoria, contextualizando sua vivência nesse processo, objetivando a construção do conhecimento.

A ação deve ser, antes de tudo, refletida, planejada, e uma vez executada, avaliada. Cabe ao educador a tarefa de alimentar o imaginário infantil, de forma que as atividades das crianças se enriqueçam, tornando se mais complexas (pelas relações que se vão estabelecendo). É necessário inserir o brincar em um projeto educativo, o que supõe sua intencionalidade, ou seja, ter objetivos e consciência da importância de sua ação em relação ao desenvolvimento e à aprendizagem infantil. 
No planejamento precisam ser explicitados os conceitos a serem trabalhados e as expectativas em relação as crianças. A partir desta definição deve-se selecionar o tipo de atividade que poderá ser utilizada para atingir tal finalidade.

Segundo Gómez (2014), a intervenção pedagógica é fundamental para a construção do conhecimento individual, e por meio desta o professor consegue acompanhar os avanços e tornar a aprendizagem significativa para o aluno, ou seja, a intervenção pedagógica mediada é para dar sentido ao que se aprende e como se aprende individualmente.

Na construção da aprendizagem o mediador na elaboração das atividades ajudará o aluno na maturação do sistema nervoso central, para a estruturação psíquica e cognitiva terem um funcionamento de acordo com as exigências do meio, por isso, sempre se deve evidenciar o "como fazer" e o "por que fazer". Neste processo ao construir o conhecimento os progressos se misturam com todas as dificuldades podendo ocasionar o retrocesso, sendo importante compreender o favorecimento das atividades de determinadas funções, e quanto mais cedo forem feitas, maior será as possibilidades de reparar. O conhecimento é construído socialmente, e as experiências significativas devem estar presentes no ambiente real.

\footnotetext{
"É importante analisar se hoje sou melhor professor do que ontem... É relevante identificar se condigo olhar meu aluno na perspectiva de seus potencias... É interessante perceber se consigo mediar as tarefas dadas sem apontar soluções aos problemas e sem esperar resultados determinados... Sou apenas um professor ou tenho atitudes de transformar." (NISTA-PICCOLO, 2013)
}

\section{CONSIDERAÇOES FINAIS}

Concluímos que ainda há muito o que se pesquisar, e ao expor nossas conclusões, lembramos que de acordo com a maioria dos autores estudados, o desenvolvimento acontece de forma contínua e sequencial; é através do movimento que a criança explora o mundo que a rodeia, se expressa e se comunica, pois ele possibilita o seu desenvolvimento como um todo, representando o que ela sente, pensa e quer. As atividades lúdicas constituem, portanto, para as crianças, um dos mais completos veículos educacionais na formação e desenvolvimento durante o período pré-escolar, pois a elas 
favorece o conhecimento do "eu" corporal, e possibilitam a organização perceptiva, ao ampliar e desenvolver a noção de espaço e tempo, de maneira a motivar a curiosidade da criança despertando o seu interesse em aprender, respeitando as fases, nos primeiros anos da criança ela se desenvolve em contato com o meio, podendo utilizar de várias formas das brincadeiras pedagógicas

As atividades lúdicas dirigidas quando são bem orientadas, tornam-se prazerosas para as realizações da criança, pois faz com que aceitem melhor as coisas que lhe são propostas, não sendo algo rígido. Assim, é importante que o professor estimule as atividades das crianças valorizando essa forma natural, prazerosa e motivadora de trabalho realizado por elas, é imprescindível que o educador conheça a todos os aspectos do desenvolvimento infantil, para o emprego de um trabalho global, dinâmico, flexível e, sobretudo, que atenda às reais necessidades, e seu nível de maturação.

Concordamos com os autores estudados quanto aos estímulos por meio de brincadeiras, buscando a atividade de maior interesse para a criança, desde que esteja ao alcance das suas habilidades e capacidades. Acreditamos, também, que o papel do professor é orientar e supervisionar; e que ele deve permitir as brincadeiras livres, sem imposições, deixando a criança atuar por livre arbítrio. Ele deve estar presente e pronto para ajudar, quando necessário, criando uma atmosfera agradável e de confiança para o desenrolar das brincadeiras; deve favorecer os estímulos apropriados e deixar que as crianças encontrem soluções para os problemas e não oferecer soluções prontas.

De acordo com Yves de Lataille, a tríade Piaget, Wallon e Vygostsky, discorrem sobre as teorias psicogenéticas a luz dos conceitos que fundamenta a interação do sujeito com o mundo por meio da afetividade, inteligência e socialização, respeitando as fases de desenvolvimento e as especificidades individuais, priorizando a interação com o outro e com o meio em que vive. Este tema tem relevância cognitiva, afetiva, social e cultural, pois a brincadeira vem desde antigamente e estimula a imaginação, muitas vezes 
sem gerar custos adicionais para a instituição educacional, pois pode utilizar espaços e recursos já existentes na mesma.

"Uma boa maneira de se compreender e avaliar a articulação, feita por um determinado autor, entre a afetividade e inteligência é analisar as concepções deste acerca do tema do juízo moral. De fato, a moralidade humana é o palco por excelência onde a afetividade e razão se encontram, via de regra, sob a forma do confronto." (YVES DE LATAILLE. p.47 1992)

Finalmente desejamos expressar o nosso ponto de vista quanto à necessidade de uma adequação, em nosso meio escolar, de uma atividade física realmente condizente com as necessidades e interesses das crianças pequenas. É necessário que todas as crianças tenham as mesmas possibilidades de vivenciar, um ambiente educativo favorável, no qual há trocas de experiência, que são indispensáveis para a sua formação afetiva, cognitiva e social.

\section{REFERÊNCIAS}

BARBIERI, Stela. Interações: onde está a arte na infância. São Paulo: Blucher, 2012. 
BORGES, Maria Fernanda; RUBIO, Juliana de Alcântara Silveira. A Educação Psicomotora como instrumento no Processo de Aprendizagem. Disponível em: http://docs.uninove.br/arte/fac/publicacoes/pdf/v4-n1-2013/M_Fernanda.pdf> Revista eletrônica Saberes da Educação- volume 4- nº1- 2013. Acesso em 01 de maio de 2018. FRIEDMANN, Adriana. O brincar na educação infantil. São Paulo: Moderna, 2012. LA TAILLE, Yves de. Teorias psicogenéticas em discussão. São Paulo: Summu,1992 NISTA-PICCOLO, Vilma Lení. Corpo em Movimento na Educação Infantil. $1^{a}$ ed. São Paulo: Telos Editora, 2012

NOGUEIRA, Liliana Azevedo; CARVALHO, Luzia Alves; PESSANHA, Fernanda Campos Lima. A Psicomotricidade na prevenção das dificuldades no processo de $\begin{array}{llll}\text { alfabetização } & \text { e } & \text { Letramento. }\end{array}$ "https://www.seer.perspectivasonline.com.br/index.php/revista_antiga/article/view/251" antiga/article/view/251"e.com.br/index.php/revista_antiga/article/view/251> Acesso em: 01 de maio de 2018

PIAGET, Jean. Seis estudos de psicologia. $24^{\circ} \mathrm{ed}$. Rio de Janeiro: Forense Universitária, 2005.

PIAGET, Jean. A Formação do Símbolo na Criança. Imitação, jogo e sonho, imagem e representação. $3^{\text {a }}$ ed. Rio de Janeiro: Zahar, 1964. 